\title{
Smoking cessation in early-pregnancy, gestational weight gain and subsequent risks of pregnancy complications
}

\author{
Lina Al-Hassany ${ }^{a, b}$, Rama J. Wahab ${ }^{a, b}$, Eric A.P. Steegers ${ }^{a, c}$, Vincent W.V. Jaddoe ${ }^{a, b}$, \\ Romy Gaillard ${ }^{\mathrm{a}, \mathrm{b}, *}$ \\ ${ }^{a}$ The Generation R Study Group, Erasmus University Medical Center, Rotterdam, the Netherlands \\ ${ }^{\mathrm{b}}$ Department of Pediatrics, Sophia Children's Hospital, Erasmus University Medical Center, Rotterdam, the Netherlands \\ ${ }^{\mathrm{c}}$ Department of Obstetrics and Gynaecology, Erasmus University Medical Center, Rotterdam, the Netherlands
}

\section{A R T I C L E IN F O}

Article history:

Received 11 May 2020

Received in revised form 13 July 2020

Accepted 20 July 2020

Available online $\mathrm{xxx}$

\section{Keywords:}

Pregnancy

Smoking cessation

Weight gain

Pregnancy complications

\begin{abstract}
A B S T R A C T
Objective: Smoking cessation is associated with weight gain. We first examined the associations of smoking cessation in early-pregnancy with gestational weight gain and subsequently evaluated the risks of pregnancy complications among women who quit smoking in early-pregnancy according to their gestational weight gain.

Methods: In a population-based prospective cohort study among 7,389 women, we measured weight in each pregnancy period. Information on smoking and pregnancy complications was obtained from questionnaires and medical records.

Results: As compared to continued smoking during pregnancy, smoking cessation in early-pregnancy was not associated with gestational weight gain. Smoking cessation in early-pregnancy was associated with decreased risks of delivering small-for-gestational-age infants (Odds Ratio (OR) 0.52 (95\% Confidence Interval (CI) $0.37,0.75)$ ), but with increased risks of pre-eclampsia (OR 2.07 (95\% CI 1.01, 4.27)) and delivering large-for-gestational-age infants (OR 2.11 (95\% CI 1.45, 3.09)). Among women who quit smoking in early-pregnancy with $>12 \mathrm{~kg}$ weight gain, the risks of pre-eclampsia and delivering large-forgestational-age infants were slightly increased.

Conclusion: As compared to continued smoking during pregnancy, smoking cessation in early-pregnancy is not associated with increased gestational weight gain. Among women who quit smoking in earlypregnancy, higher gestational weight gain does not strongly affect their risks of pregnancy complications.
\end{abstract}

(c) 2020 Elsevier B.V. All rights reserved.

\section{Introduction}

Maternal smoking during pregnancy is a major public health problem leading to increased risks of pregnancy complications $[1,2]$. Despite strong recommendations to quit smoking before pregnancy, approximately $15 \%$ of women smoke at the start of pregnancy and $8 \%$ of women continue to smoke during pregnancy [3-5]. Women might be reluctant to quit smoking due to concerns of potential unfavorable effects subsequent to smoking cessation, such as excessive weight gain [6-8]. In general, excessive weight gain is a well-known side effect of smoking cessation, and might discourage women from cessation attempts [9]. During pregnancy, excessive weight gain is a risk

\footnotetext{
* Corresponding author at: The Generation R Study Group, Erasmus University Medical Center, PO Box 2040, 3000 CA, Rotterdam, the Netherlands.

E-mail address: r.gaillard@erasmusmc.nl (R. Gaillard).
}

factor for pregnancy complications [10-12]. Thus far, only a few studies assessed the association of smoking cessation in earlypregnancy with total gestational weight gain. These studies suggested that smoking cessation in early-pregnancy might be associated with a moderate increased risk of excessive gestational weight gain, but no information about the pattern of subsequent gestational weight gain throughout pregnancy is available [13-19]. It also remains unknown whether gestational weight gain subsequent to smoking cessation in early-pregnancy affects the well-known benefits of smoking cessation on pregnancy complications.

Therefore, in a population-based prospective cohort study among 7,389 pregnant women, we first examined whether smoking cessation in early-pregnancy is associated with subsequent gestational weight gain. Second, we evaluated the risks of pregnancy complications among women who quit smoking in early-pregnancy according to their subsequent gestational weight gain. 


\section{Methods}

Study design and participants

This study was embedded in the Generation $\mathrm{R}$ study, a population-based prospective cohort study in Rotterdam, the Netherlands [20]. All pregnant women were enrolled between 2001 and 2005. Response rate at baseline was $61 \%$, calculated by dividing the number of participating live born children by the total number of live born children born in the study area during the inclusion period. 7,738 women had information on smoking during pregnancy. After excluding women with less than two weight measurements during pregnancy and excluding non-singleton live births, population for analysis included 7,389 women (Supplemental Fig. S1).

\section{Smoking during pregnancy}

We obtained information on maternal smoking during pregnancy through questionnaires (never smoking during pregnancy, smoking cessation in early-pregnancy or continued smoking during pregnancy), as described previously [21]. We compared the effect of smoking cessation in early-pregnancy to continued smoking during pregnancy, to explore the potential health benefits among women who are motivated to quit smoking once they known they are pregnant.

\section{Weight gain during pregnancy}

Maternal weight was repeatedly measured in early- $(<18$ weeks), mid- (18-25 weeks) and late-pregnancy ( $>25$ weeks) without shoes and heavy clothing [20]. Information about maternal weight before pregnancy was obtained by questionnaire (correlation coefficient with weight at enrolment 0.95 ). Period specific weight gain was calculated as the difference between two weight measurements divided by difference in gestational age. Information about maximum weight during pregnancy was self-reported 2 months after delivery (correlation coefficient with weight measurement at 30 weeks gestation 0.96). Because of larger numbers of measurements available, we used gestational weight gain until 30 weeks for main analyses [22]. Among women with information on maximum weight available, we defined inadequate and excessive gestational weight gain in relation to maternal pre-pregnancy BMI according to the US Institute of Medicine (IOM) Guidelines [23].

\section{Pregnancy complications}

Information on gestational hypertension, pre-eclampsia, gestational diabetes and gestational age and weight at birth was obtained from medical records. Pre-term birth was defined as a gestational age $<37$ weeks at birth. We defined small- and largefor-gestational-age at birth as a fetal sex and gestational ageadjusted birth weight below the 10th percentile and above the 90th percentile in the study cohort, respectively [24]. We examined the associations with composite outcomes (maternal pregnancy complications and adverse birth outcomes) and with complications separately.

\section{Covariates}

Information about maternal age, ethnicity, education level, parity, folic acid supplementation and alcohol consumption was obtained through questionnaires [20].

\section{Statistical analysis}

First, we assessed population characteristics according to smoking status. Second, we assessed the associations of smoking cessation with weight gain in each pregnancy period and until 30 weeks of gestation using linear regression models. We constructed standard deviation scores (SDS) of weight gain to compare the effect estimates between different pregnancy periods and used weight gain in kilogram/week for clinical interpretability. We assessed the associations of smoking cessation with the risks of inadequate and excessive gestational weight gain using logistic regression models. Third, with logistic regression models, we assessed the risks of pregnancy complications among women who quit smoking in early-pregnancy according to the amount of weight gain until 30 weeks of gestation in tertiles, compared to women who continued smoking during pregnancy. To further assess whether the combined effects of smoking cessation in earlypregnancy and gestational weight gain were different from the separate effects, we tested for interaction between these exposures on each pregnancy complication. We constructed different models: basic model (adjusted for gestational age at intake and weight measurement), confounder model (basic model additionally adjusted for maternal age, ethnicity, education level, parity, folic acid supplementation, and alcohol consumption during pregnancy), and maternal BMI model (confounder model additionally adjusted for maternal pre-pregnancy BMI). Confounder selection was based on literature and included in the model when associated with both exposure and outcome and changes in effect estimates of $>10 \%[12,25-30]$. To deal with missing data, we performed multiple imputations of covariates. Analyses were performed using

Statistical Package of Social Sciences version 24.0 for Windows (SPSS Inc., Chicago, IL., USA).

\section{Results}

\section{Subject characteristics}

Table 1 shows that in our population 1,382 (18.7\%) women continued smoking during pregnancy, 641 (8.7 \%) women quitted smoking in early-pregnancy and 5,366 (72.6 \%) women never smoked during pregnancy. Women who quit smoking in earlypregnancy had a lower pre-pregnancy BMI and higher maximum gestational weight gain, compared to women who continued smoking during pregnancy.

\section{Smoking status and gestational weight gain}

Table 2 shows that, as compared to continued smoking during pregnancy, smoking cessation in early-pregnancy was not associated with gestational weight gain per pregnancy period or until 30 weeks gestation. As compared to continued smoking during pregnancy, never smoking during pregnancy was associated with a lower gestational weight gain in each pregnancy period ( $p$-values $<0.05$ ). Additional adjustment for maternal pre-pregnancy BMI did not materially affect associations. Associations with gestational weight gain in kilogram/ week were similar (Supplemental Table S1). As compared to continued smoking during pregnancy, smoking cessation in earlypregnancy was not associated with the risks of inadequate or excessive weight gain, whereas never smoking during pregnancy was associated with decreased risks of excessive gestational weight gain (Odds Ratio (OR) 0.54 (95 \% Confidence Interval (CI) $0.42,0.69)$ ), but not with risks of inadequate gestational weight gain (Fig. 1). 
Table 1

Characteristics of the study population according to maternal smoking status during pregnancy.

\begin{tabular}{|c|c|c|c|c|}
\hline & \multicolumn{3}{|c|}{ Maternal smoking status during pregnancy } & \multirow[t]{2}{*}{ P-value ${ }^{1}$} \\
\hline & $\begin{array}{l}\text { Continued smoking during } \\
\text { pregnancy } \\
(\mathrm{n}=1,382)\end{array}$ & $\begin{array}{l}\text { Smoking cessation in } \\
\text { early-pregnancy }(n=641)\end{array}$ & $\begin{array}{l}\text { Never smoking during } \\
\text { pregnancy } \\
(\mathrm{n}=5,366)\end{array}$ & \\
\hline \multicolumn{5}{|l|}{ Maternal characteristics } \\
\hline Age at enrolment, median (95\%), years & $28.4(19.4,37.5)$ & $30.1(20.0,37.8)$ & $30.6(20.9,38.0)$ & $<0.01$ \\
\hline Height, mean (SD), cm & $166.9(7.1)$ & $168.2(7.0)$ & $167.4(7.4)$ & $<0.01$ \\
\hline Gestational age at intake, median (95\%), weeks & $14.1(10.4,22.2)$ & $13.4(10.1,20.9)$ & $13.9(10.9,22.4)$ & $<0.01$ \\
\hline Ethnicity, no. Dutch (\%) & $654(47.3)$ & $332(51.8)$ & $2,662(49.6)$ & $<0.01$ \\
\hline Education level, no. higher phase (\%) & $240(17.4)$ & $265(41.3)$ & $2,511(46.8)$ & $<0.01$ \\
\hline Pre-pregnancy BMI, median (95\%), kg/m² & $22.5(18.2,32.7)$ & $22.3(18.4,31.6)$ & $22.7(18.7,32.3)$ & 0.31 \\
\hline BMI class overweight/obese, no. (\%) & $331(24.0)$ & $140(21.8)$ & $1,356(25.3)$ & 0.01 \\
\hline \multicolumn{5}{|l|}{ Gestational weight gain ${ }^{2}$, mean (SD), kg } \\
\hline Early-pregnancy weight gain & $3.2(3.6)$ & $2.8(3.5)$ & $2.0(3.3)$ & $<0.01$ \\
\hline Mid-pregnancy weight gain & $3.3(2.5)$ & $3.7(2.3)$ & $3.1(2.3)$ & $<0.01$ \\
\hline Late-pregnancy weight gain & $5.2(3.0)$ & $5.6(2.7)$ & $4.9(2.7)$ & $<0.01$ \\
\hline Maximum gestational weight gain & $16.2(6.5)$ & $17.3(6.3)$ & $14.4(5.6)$ & $<0.01$ \\
\hline Parity, no. nulliparous (\%) & $766(55.4)$ & $438(68.3)$ & $2,993(55.8)$ & $<0.01$ \\
\hline Alcohol use during pregnancy, no. (\%), continued & $498(36.0)$ & $292(45.6)$ & $1,903(35.5)$ & $<0.01$ \\
\hline Folic acid supplementation during pregnancy, no. (\%), never & $423(30.6)$ & $119(18.6)$ & $1,256(23.4)$ & $<0.01$ \\
\hline \multicolumn{5}{|l|}{ Maternal pregnancy complications } \\
\hline Gestational hypertensive disorder, no. (\%) & $74(5.4)$ & $49(7.6)$ & $302(5.6)$ & 0.11 \\
\hline Gestational hypertension & $54(3.9)$ & $29(4.5)$ & $194(3.6)$ & 0.49 \\
\hline Pre-eclampsia & $20(1.4)$ & $20(3.1)$ & $108(2.0)$ & 0.05 \\
\hline Gestational diabetes, no. (\%) & $15(1.1)$ & $2(0.3)$ & $57(1.1)$ & 0.18 \\
\hline \multicolumn{5}{|l|}{ Birth outcomes } \\
\hline Gestational age at birth, median (95\%), weeks & $39.9(36.4,42.0)$ & $40.0(36.9,42.0)$ & $40.1(37.1,42.1)$ & $<0.01$ \\
\hline Birth weight, mean (SD), grams & $3260.4(541.2)$ & $3423.5(559.0)$ & $3458.0(546.6)$ & $<0.01$ \\
\hline Gender, no. girl (\%) & $634(45.9)$ & $329(51.3)$ & $2,703(50.4)$ & 0.01 \\
\hline Preterm birth, no. (\%) & $90(6.5)$ & $32(5.0)$ & $242(4.5)$ & 0.01 \\
\hline Small-for-gestational-age infants, no. (\%) & $218(15.8)$ & $57(8.9)$ & $449(8.4)$ & $<0.01$ \\
\hline Large-for-gestational-age infants, no. (\%) & $71(5.1)$ & $70(10.9)$ & $572(10.7)$ & $<0.01$ \\
\hline
\end{tabular}

1 Differences in subject characteristics between the groups were evaluated using one-way ANOVA tests for continuous variables and chi-square tests for proportions.

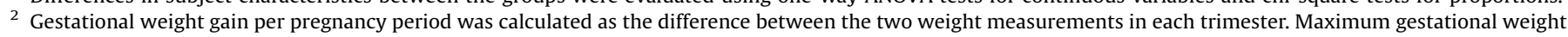
gain was defined as the difference between pre-pregnancy weight and the highest self-reported weight at pregnancy.

Table 2

Associations of maternal smoking status during pregnancy with gestational weight gain ${ }^{1}$.

\begin{tabular}{|c|c|c|c|c|}
\hline Maternal smoking status during pregnancy & $\begin{array}{l}\text { Early-pregnancy weight } \\
\text { gain } \\
\text { Difference in SDS (95\% CI) }\end{array}$ & $\begin{array}{l}\text { Mid-pregnancy weight } \\
\text { gain } \\
\text { Difference in SDS (95 \% CI) }\end{array}$ & $\begin{array}{l}\text { Late-pregnancy weight } \\
\text { gain } \\
\text { Difference in SDS (95\% CI) }\end{array}$ & $\begin{array}{l}\text { Total pregnancy weight gain } \\
\text { Difference in SDS (95\% CI) }\end{array}$ \\
\hline $\begin{array}{l}\text { Continued smoking during pregnancy }(\mathbf{n}= \\
1,382)\end{array}$ & Reference & Reference & Reference & Reference \\
\hline \multicolumn{5}{|l|}{ Smoking cessation in early-pregnancy $(n=641)$} \\
\hline Confounder model ${ }^{2}$ & $\begin{array}{l}-0.08 \\
(-0.19,0.03)\end{array}$ & $\begin{array}{l}0.05 \\
(-0.06,0.15)\end{array}$ & $\begin{array}{l}0.08 \\
(-0.02,0.18)\end{array}$ & $\begin{array}{l}0.04 \\
(-0.06,0.14)\end{array}$ \\
\hline Maternal BMI model ${ }^{3}$ & $\begin{array}{l}-0.09 \\
(-0.20,0.02)\end{array}$ & $\begin{array}{l}0.08 \\
(-0.03,0.19)\end{array}$ & $\begin{array}{l}0.08 \\
(-0.02,0.18)\end{array}$ & $\begin{array}{l}0.04 \\
(-0.06,0.14)\end{array}$ \\
\hline \multicolumn{5}{|l|}{ Never smoking during pregnancy $(\mathbf{n}=5,366)$} \\
\hline Confounder model ${ }^{2}$ & $\begin{array}{l}-0.34 \\
(-0.41,-0.26)^{*}\end{array}$ & $\begin{array}{l}-0.15 \\
(-0.22,-0.09)^{*}\end{array}$ & $\begin{array}{l}-0.12 \\
(-0.18,-0.05)^{*}\end{array}$ & $\begin{array}{l}-0.35 \\
(-0.42,-0.28)^{*}\end{array}$ \\
\hline Maternal BMI model ${ }^{3}$ & $\begin{array}{l}-0.33 \\
(-0.41,-0.26)^{*}\end{array}$ & $\begin{array}{l}-0.13 \\
(-0.21,-0.06)^{*}\end{array}$ & $\begin{array}{l}-0.12 \\
(-0.19,-0.05)^{*}\end{array}$ & $\begin{array}{l}-0.34 \\
(-0.40,-0.27)^{*}\end{array}$ \\
\hline
\end{tabular}

${ }^{1}$ Values represent regression coefficients (95\% confidence interval) from linear regression models that reflect the differences in weight gain per week in standard deviation

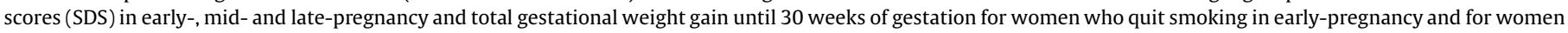
who continued smoking during pregnancy, as compared to those who never smoked during pregnancy. Estimates are based on multiple imputed data.

${ }^{2}$ Confounder model includes adjustment for gestational age at enrolment, maternal age, ethnicity, education level, parity, folic acid supplementation and alcohol consumption during pregnancy.

3 Maternal BMI model includes the confounder model additionally adjusted for maternal pre-pregnancy body mass index.

${ }^{*} \mathrm{P}<0.01$.

Smoking status, gestational weight gain and pregnancy complications

Table 3 shows that, overall, as compared to women who continued smoking during pregnancy, women who quit smoking in early-pregnancy had increased risks of pre-eclampsia (OR 2.07 (95 \% CI 1.01, 4.27)), but not of other maternal pregnancy complications. Their risks were similar to women who never smoked during pregnancy. The amount of gestational weight gain did not have a strong effect on the observed associations (all pvalues for interaction $>0.05$ ). Among women who quit smoking in early-pregnancy, the risks of pre-eclampsia were highest among women with low or high gestational weight gain, as compared to 


\section{Risk of inadequate gestational weight gain}

\section{Risk of excessive gestational weight gain}

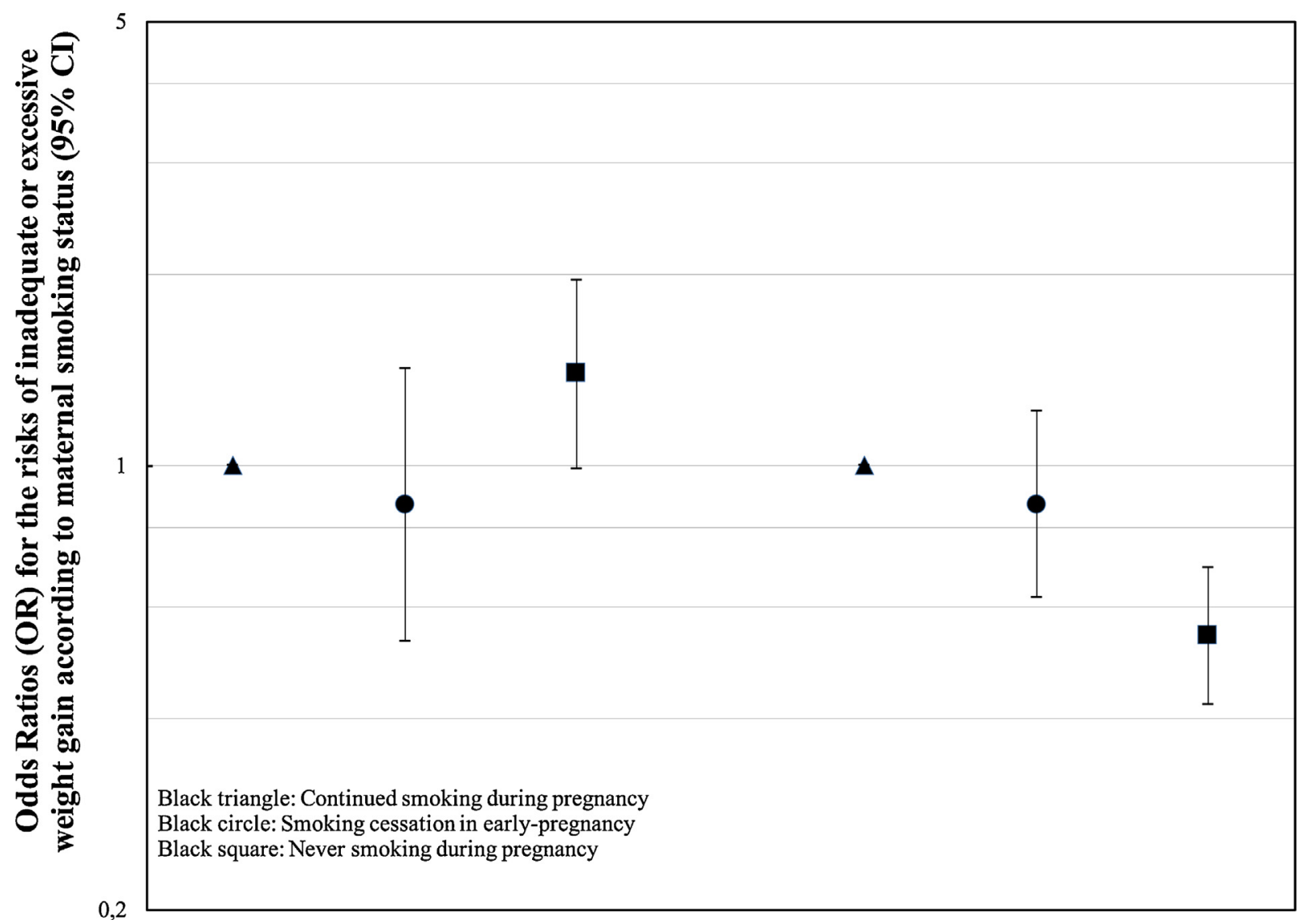

Fig. 1. Association of maternal smoking status during pregnancy with the risks of inadequate or excessive gestational weight gain ${ }^{1}$.

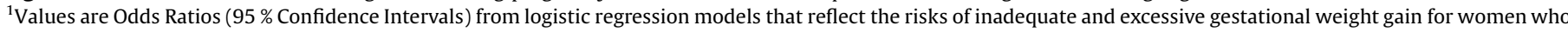

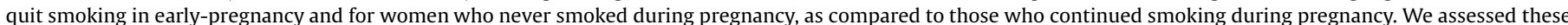

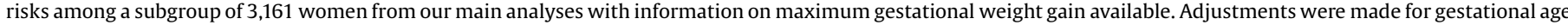
at enrolment, maternal age, ethnicity, education level, parity, folic acid supplementation use, alcohol consumption during pregnancy and gestational age at birth.

women who continued smoking during pregnancy (OR $3.70(95 \%$ CI 1.39, 9.86), OR 2.36 (95 \% CI 1.01, 5.52) respectively). Adjustment for maternal pre-pregnancy BMI did not explain these associations.

Overall, as compared to women who continued smoking in pregnancy, women who quit smoking in early-pregnancy tended to have lower risks of any adverse birth outcome (Table 4). When we explored individual birth outcomes, we observed that women who quit smoking in early-pregnancy had decreased risks of delivering small-for-gestational-age infants (OR 0.52 (95\% 0.37, 0.75 ) and increased risks of delivering large-for-gestational-age infants (OR 2.11 (95\% CI 1.45, 3.09), as compared to women who continued smoking during pregnancy. These risks were comparable to the risks of women who never smoked during pregnancy. We observed a significant interaction between smoking status and total gestational weight gain on the composite of adverse birth outcomes ( $p$-value 0.02 ), but not on each adverse birth outcome separately ( $p$-value>0.05). When taking gestational weight gain into account, women who quit smoking in early-pregnancy with a gestational weight gain $>12 \mathrm{~kg}$ had the lowest risks of delivering small-for-gestational-age infants (OR 0.36 (95\% CI 0.21, 0.63), whereas their risks of delivering large-for-gestational-age infants were the highest (OR 2.64 (95\% CI 1.68, 4.14), as compared to women who continued smoking during pregnancy. Additional adjustment for maternal pre-pregnancy BMI did not explain the associations.

\section{Discussion}

We observed that smoking cessation in early-pregnancy was not associated with a higher period-specific or total gestational weight gain, as compared to continued smoking during pregnancy. As compared to women who continued smoking during pregnancy, women who quit smoking in early-pregnancy had lower risks of delivering small-for-gestational-age infants, but increased risks of pre-eclampsia and delivering large-for-gestational-age infants. These risks were comparable to women who never smoked during pregnancy. The influence of gestational weight gain on these associations was small.

\section{Interpretation main findings}

Benefits of smoking cessation prior to pregnancy are wellknown. However, still a substantial amount of pregnant women smoke during pregnancy, which leads to strongly increased risks of adverse pregnancy outcomes [2]. In non-pregnant populations, smoking cessation is associated with weight gain and subsequent adverse health outcomes, including type 2 diabetes [8]. The effects of smoking on weight gain might be caused through increased fat mass levels by altered food satiation and hormone leptin mechanisms [31]. Concerns about weight gain after smoking cessation is commonly cited as a reason to be reluctant to quit 
Table 3

Associations of maternal smoking status during pregnancy and gestational weight gain with the risk of maternal pregnancy complications ${ }^{1}$.

\begin{tabular}{|c|c|c|c|}
\hline & $\begin{array}{l}\text { OR }(95 \% \mathrm{CI}) \\
\text { Confounder model }^{2}\end{array}$ & $\begin{array}{l}\text { OR }(95 \% \mathrm{CI}) \\
\text { Maternal BMI model }^{3}\end{array}$ & $\begin{array}{l}\text { P-value } \\
\text { Interaction term }^{4}\end{array}$ \\
\hline Composite of maternal pregnancy complications $(n=418)$ & & & 0.70 \\
\hline Continued smoking during pregnancy & Reference & Reference & \\
\hline Smoking cessation in early-pregnancy & $1.16(0.77,1.75)$ & $1.18(0.77,1.79)$ & \\
\hline First tertile of weight gain $(<9 \mathrm{~kg})$ & $0.95(0.42,2.14)$ & $0.70(0.30,1.63)$ & \\
\hline Second tertile of weight gain $(9-12 \mathrm{~kg})$ & $0.84(0.41,1.72)$ & $0.91(0.44,1.90)$ & \\
\hline Third tertile of weight gain (>12 kg) & $1.47(0.90,2.39)$ & $1.61(0.98,2.65)$ & \\
\hline Never smoking during pregnancy & $1.14(0.86,1.51)$ & $1.13(0.84,1.51)$ & \\
\hline Gestational hypertension $(n=238$ ) & & & 0.92 \\
\hline Continued smoking during pregnancy & Reference & Reference & \\
\hline Smoking cessation in early-pregnancy & $1.00(0.59,1.67)$ & $1.02(0.60,1.73)$ & \\
\hline First tertile of weight gain ( $<9 \mathrm{~kg})$ & $0.20(0.03,1.46)$ & $0.13(0.02,0.96)^{*}$ & \\
\hline Second tertile of weight gain $(9-12 \mathrm{~kg})$ & $0.95(0.42,2.18)$ & $1.09(0.47,2.52)$ & \\
\hline Third tertile of weight gain $(>12 \mathrm{~kg})$ & $1.37(0.75,2.50)$ & $1.57(0.85,2.90)$ & \\
\hline Never smoking during pregnancy & $0.99(0.69,1.41)$ & $0.97(0.67,1.39)$ & \\
\hline Pre-eclampsia $(n=122)$ & & & 0.33 \\
\hline Continued smoking during pregnancy & Reference & Reference & \\
\hline Smoking cessation in early-pregnancy & $2.07(1.01,4.27)^{*}$ & $2.00(0.97,4.13)$ & \\
\hline First tertile of weight gain $(<9 \mathrm{~kg})$ & $3.70(1.39,9.86)^{* *}$ & $3.01(1.11,8.17)^{*}$ & \\
\hline Second tertile of weight gain $(9-12 \mathrm{~kg})$ & $0.44(0.07,2.88)$ & $0.45(0.06,3.43)$ & \\
\hline Third tertile of weight gain $(>12 \mathrm{~kg})$ & $2.36(1.01,5.52)^{*}$ & $2.39(1.02,5.62)^{*}$ & \\
\hline Never smoking during pregnancy & $1.57(0.89,2.78)$ & $1.54(0.87,2.72)$ & \\
\hline Gestational diabetes mellitus $(n=65)$ & & & 0.35 \\
\hline Continued smoking during pregnancy & Reference & Reference & \\
\hline Smoking cessation in early-pregnancy & $0.39(0.09,1.78)$ & $0.38(0.09,1.74)$ & \\
\hline First tertile of weight gain (<9 kg) & NA & NA & \\
\hline Second tertile of weight gain $(9-12 \mathrm{~kg})$ & $0.65(0.08,5.04)$ & $0.73(0.09,5.72)$ & \\
\hline Third tertile of weight gain $(>12 \mathrm{~kg})$ & $0.42(0.05,3.26)$ & $0.46(0.06,3.61)$ & \\
\hline Never smoking during pregnancy & $1.02(0.53,1.97)$ & $0.97(0.50,1.86)$ & \\
\hline
\end{tabular}

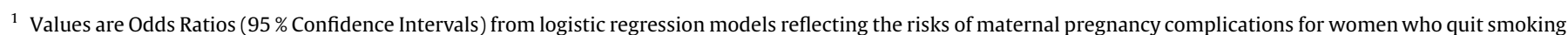

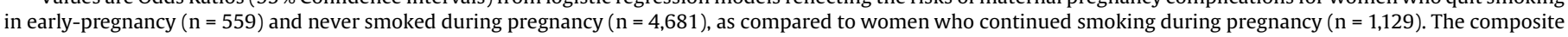

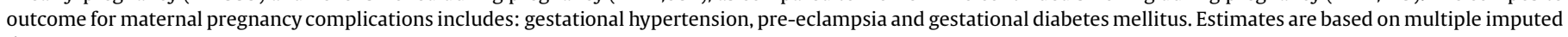
data.

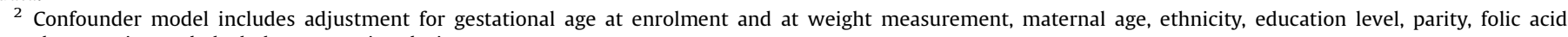
supplementation and alcohol consumption during pregnancy.

3 Maternal BMI model includes the confounder model additionally adjusted for maternal pre-pregnancy body mass index.

4 We tested the following interaction term between smoking status*total gestational weight gain.

$\mathrm{P}<0.05$

$\mathrm{P}<0.01$

smoking [32]. In pregnancy, excessive weight gain is a well-known risk factor for pregnancy complications $[10,33]$. Whether smoking cessation in early-pregnancy is also associated with subsequent higher gestational weight gain and whether this attenuates the positive effects of smoking cessation on pregnancy outcomes remains unclear.

Few studies examined the associations of smoking cessation in pregnancy with gestational weight gain and reported inconsistent findings [13,19,34,35]. A Swedish cohort study among 1,753 pregnant women, reported that smoking cessation in earlypregnancy was associated with a higher amount of gestational weight, as compared to never smoking or continued smoking during pregnancy [14]. A Danish study among 1,774 women showed that women who quit smoking gained more weight during pregnancy than women who never smoked during pregnancy [13]. Contrarily, a study among 357 high risk pregnant women participating in a smoking intervention program, reported no difference in gestational weight gain between women who quit smoking and women who continued smoking during pregnancy [15]. In line with the latter study, we observed no association of smoking cessation in early-pregnancy with gestational weight gain throughout pregnancy, as compared to continued smoking during pregnancy. Women who never smoked during pregnancy had the lowest amount of gestational weight gain, which might reflect an overall healthier lifestyle. Discrepancy between our study and previous observational studies observing an association of smoking cessation in early-pregnancy with higher total gestational weight gain, might be due to the lack of adjustment for multiple confounders in previous studies, but also to our relatively healthy population. Further studies are needed to replicate our findings among higher risk populations. Findings should be addressed more often in clinical practice to women who hesitate to quit smoking in pregnancy because of weight gain concerns.

Smoking cessation in early-pregnancy is associated with major offspring health benefits. Rates of spontaneous preterm birth and small-for-gestational-age infants become similar to those of women who never smoked during pregnancy [5]. Contrarily, risks of pre-eclampsia and delivering large-for-gestational-age infants have been suggested to be higher among women who quit smoking in early-pregnancy than in those who continued smoking during pregnancy [36,37]. In line with previous studies, we observed that smoking cessation in early-pregnancy was associated with lower risks of delivering small-for-gestational-age infants, whereas the risks of pre-eclampsia and delivering large-for-gestational-age infants were higher, as compared to continued smoking during pregnancy and were largely comparable to never smoking during pregnancy. The effects were only slightly affected by the amount of gestational weight gain, with slightly lower risks of delivering small-for-gestational-age infants and higher risks of pre-eclampsia and delivering large-for-gestational-age infants among women who quit smoking in early-pregnancy and gained high amounts of gestational weight. These findings suggests that other mechanisms than the amount of gestational weight gain, may explain the observed associations. Smoking during pregnancy might influence intrauterine fetal growth directly by toxic effects $[38,39]$. 
Table 4

Associations of maternal smoking status during pregnancy and gestational weight gain with the risk of adverse birth outcomes ${ }^{1}$.

\begin{tabular}{|c|c|c|c|c|}
\hline $\begin{array}{l}\text { OR }(95 \% \mathrm{CI}) \\
\text { Confounder model }^{2}\end{array}$ & \multicolumn{3}{|c|}{$\begin{array}{l}\text { OR }(95 \% \mathrm{CI}) \\
\text { Maternal BMI model }^{3}\end{array}$} & \multirow{2}{*}{$\begin{array}{l}\begin{array}{l}\text { P-value } \\
\text { Interaction term }\end{array} \\
0.02^{*}\end{array}$} \\
\hline Composite of adverse birth outcomes $(n=1450)$ & & & & \\
\hline Continued smoking during pregnancy & Reference & Reference & & \\
\hline Smoking cessation in early-pregnancy & $0.86(0.68,1.10)$ & $0.86(0.68,1.10)$ & & \\
\hline First tertile of weight gain $(<9 \mathrm{~kg})$ & $0.89(0.58,1.37)$ & $0.86(0.56,1$ & 33) & \\
\hline Second tertile of weight gain $(9-12 \mathrm{~kg})$ & $0.93(0.64,1.35)$ & $0.93(0.64,1$ & 36) & \\
\hline Third tertile of weight gain $(>12 \mathrm{~kg})$ & $0.81(0.59,1.12)$ & $0.82(0.59,1$ & 13) & \\
\hline Never smoking during pregnancy & $0.81(0.69,0.95)^{* *}$ & $0.81(0.69,0.94)^{* *}$ & & \\
\hline Preterm birth $(n=275)$ & & & & 0.56 \\
\hline Continued smoking during pregnancy & Reference & Reference & & \\
\hline Smoking cessation in early-pregnancy & $0.74(0.47,1.19)$ & $0.74(0.47,1.19)$ & & \\
\hline First tertile of weight gain $(<9 \mathrm{~kg})$ & $1.13(0.55,2.34)$ & & $1.12(0.54,2.32)$ & \\
\hline Second tertile of weight gain $(9-12 \mathrm{~kg})$ & $0.79(0.37,1.68)$ & & $0.79(0.37,1.68)$ & \\
\hline Third tertile of weight gain $(>12 \mathrm{~kg})$ & $0.53(0.26,1.09)$ & & $0.54(0.26,1.10)$ & \\
\hline Never smoking during pregnancy & $0.63(0.46,0.85)^{* *}$ & $0.63(0.46,0.85)^{* *}$ & & \\
\hline Small-for-gestational-age infants $(n=602)$ & & & & 0.96 \\
\hline Continued smoking during pregnancy & Reference & Reference & & \\
\hline Smoking cessation in early-pregnancy & $0.52(0.37,0.75)^{* *}$ & $0.52(0.37,0.75)^{* * *}$ & & \\
\hline First tertile of weight gain $(<9 \mathrm{~kg})$ & $0.76(0.43,1.34)$ & & $0.79(0.44,1.40)$ & \\
\hline Second tertile of weight gain $(9-12 \mathrm{~kg})$ & $0.60(0.34,1.06)$ & & $0.59(0.34,1.04)$ & \\
\hline Third tertile of weight gain $(>12 \mathrm{~kg})$ & $0.36(0.21,0.63)^{* *}$ & & $0.36(0.21,0.63)^{* *}$ & \\
\hline Never smoking during pregnancy & $0.55(0.44,0.67)^{* *}$ & $0.55(0.45,0.68)^{* *}$ & & \\
\hline Large-for-gestational-age infants $(n=621)$ & & & & 0.27 \\
\hline Continued smoking during pregnancy & Reference & Reference & & \\
\hline Smoking cessation in early-pregnancy & $2.11(1.45,3.09)^{* *}$ & $2.13(1.45,3.12)^{* *}$ & & \\
\hline First tertile of weight gain $(<9 \mathrm{~kg})$ & $1.17(0.55,2.49)$ & & $1.01(0.48,2.14)$ & \\
\hline Second tertile of weight gain $(9-12 \mathrm{~kg})$ & $2.07(1.19,3.59)^{*}$ & & $2.13(1.22,3.72)^{* *}$ & \\
\hline Third tertile of weight gain (>12 kg) & $2.64(1.68,4.14)^{* *}$ & & $2.79(1.77,4.39)^{* *}$ & \\
\hline Never smoking during pregnancy & $1.85(1.39,2.47)^{* *}$ & $1.81(1.36,2.42)^{* *}$ & & \\
\hline
\end{tabular}

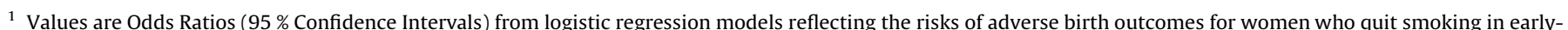

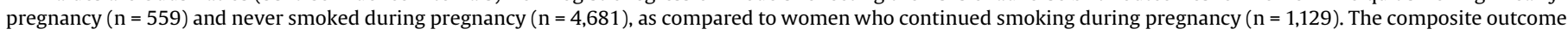

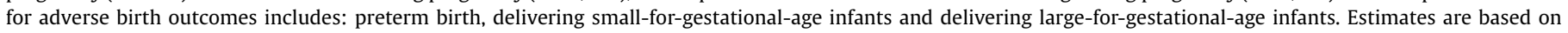
multiple imputed data.

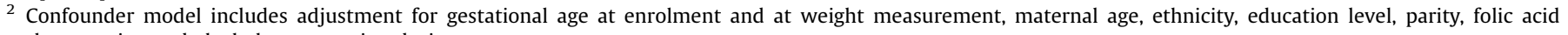
supplementation and alcohol consumption during pregnancy.

3 Maternal BMI model includes the confounder model additionally adjusted for maternal pre-pregnancy body mass index.

4 We tested the following interaction term between smoking status*total gestational weight gain.

${ }^{*} \mathrm{P}<0.05$.

$\mathrm{P}<0.01$.

Contrarily, the protective role of smoking on pre-eclampsia might be explained by the effects of carbon monoxide on placental growth and nicotine on the antioxidant systems [40]. Thus, our findings suggest that, as compared to continued smoking, smoking cessation in early-pregnancy is associated with lower risks of delivering small-for-gestational-age infants, but higher risks of pre-eclampsia and delivering large-for-gestational-age, comparable to women who never smoked during pregnancy. These effects are not strongly influenced by the amount of gestational weight gain. The benefits of smoking cessation in early-pregnancy on risks of delivering small-for-gestational-age infants clearly outweigh the potential risks of excessive gestational weight gain and its negative effect on pregnancy outcomes. Preventive strategies should actively support smoking cessation in early-pregnancy among women who still smoke at the start of their pregnancy. Since risks of pregnancy complications were slightly higher among those women who quit smoking in early-pregnancy with higher gestational weight gain, future preventive strategies should also consider addressing excessive weight gain among this specific group of women.

\section{Methodological considerations}

The most important strength of our study was the prospective data collection from early-pregnancy onwards of a large population with measurements of maternal weight in each pregnancy period. The nonresponse at baseline would have led to biased effect estimates if the associations were different between those included and not, but this seems unlikely because biased estimates in large cohort studies often arise from loss to follow-up rather than from nonresponse at baseline [41]. We had relatively low numbers of cases of pregnancy complications, which might indicate a selection towards a relatively healthy population and might have affected the generalizability of our findings. Selfreported data might lead to non-differential misclassification bias and an underestimation of our results $[42,43]$. However, previous studies have shown that self-reported data on smoking status is useful and highly correlated to biomarkers of tobacco exposure. We observed high correlations between weight measured in earlyand late-pregnancy with self-reported pre-pregnancy weight and maximum weight, respectively, but self-reported weight might lead to misclassification. We had detailed information about a large number of potential confounders, but residual confounding might still be an issue.

\section{Conclusion}

As compared to continued smoking during pregnancy, smoking cessation in early-pregnancy was not associated with increased gestational weight gain. As compared to women who continued smoking during pregnancy, women who quit smoking in earlypregnancy have lower risks of delivering small-for-gestational-age infants, but higher risks of pre-eclampsia and delivering large-forgestational-age infants. Risks are comparable to women who never smoked during pregnancy and not strongly influenced by the amount of gestational weight gain. 


\section{Contribution to authorship}

LA, RW, and RG designed and constructed the research, wrote the paper and had primary responsibility for the final content. LA, RW and RG carried out the statistical analysis. VWVJ and EAS coordinated data acquisition and critically reviewed and revised the manuscript. All authors approved the final manuscript and agree to be accountable for all aspects of the work.

\section{Sources of funding}

The Generation R Study is financially supported by the Erasmus Medical Center, Rotterdam, the Erasmus University Rotterdam and the Netherlands Organization for Health Research and Development. Romy Gaillard received funding from the Dutch Heart Foundation (grant number 2017T013), the Dutch Diabetes Foundation (grant number 2017.81.002) and the Netherlands Organization for Health Research and Development (NWO, ZonMW, grant number 543003109). Vincent Jaddoe received a European Research Council Consolidator Grant (ERC2014-CoG-648916).

\section{Details of ethical approval}

The study protocol was approved by the Medical Ethical Committee of the Erasmus Medical Centre, Rotterdam (MEC 198.782/2001/31, MEC 217.595/2002/202, MEC 2007-413). Written informed consent was obtained from all participating mothers.

\section{Declaration of Competing Interest}

The authors declare that they have no known competing financial interests or personal relationships that could have appeared to influence the work reported in this paper.

\section{Acknowledgements}

The Generation R Study is conducted by the Erasmus Medical Center in close collaboration with the School of Law and Faculty of Social Sciences of the Erasmus University Rotterdam, the Municipal Health Service Rotterdam area, Rotterdam, the Rotterdam Homecare Foundation, Rotterdam and the Stichting Trombosedienst and Artsenlaboratorium Rijnmond (STAR), Rotterdam. We gratefully acknowledge the contribution of participating mothers, general practitioners, hospitals, midwives and pharmacies in Rotterdam.

\section{Appendix A. Supplementary data}

Supplementary material related to this article can be found, in the online version, at doi:https://doi.org/10.1016/j. ejogrb.2020.07.040.

\section{References}

[1] Bernstein IM, Mongeon JA, Badger GJ, Solomon L, Heil SH, Higgins ST. Maternal smoking and its association with birth weight. Obstet Gynecol 2005;106(5 Pt 1):986-91.

[2] Castles A, Adams EK, Melvin CL, Kelsch C, Boulton ML. Effects of smoking during pregnancy. Five meta-analyses. Am J Prev Med 1999;16(3):208-15

[3] Lange S, Probst C, Rehm J, Popova S. National, regional, and global prevalence of smoking during pregnancy in the general population: a systematic review and meta-analysis. Lancet Glob Health 2018;6(7):e769-76.

[4] Tong VT, Dietz PM, Farr SL, D’Angelo DV, England LJ. Estimates of smoking before and during pregnancy, and smoking cessation during pregnancy: comparing two population-based data sources. Public Health Rep 2013;128 (3):179-88.

[5] McCowan LM, Dekker GA, Chan E, Stewart A, Chappell LC, Hunter M, et al. Spontaneous preterm birth and small for gestational age infants in women who stop smoking early in pregnancy: prospective cohort study. BMJ 2009;338:b1081.

[6] Williamson DF, Madans J, Anda RF, Kleinman JC, Giovino GA, Byers T. Smoking cessation and severity of weight gain in a national cohort. $\mathrm{N}$ Engl J Med 1991;324(11):739-45.

[7] Aubin HJ, Farley A, Lycett D, Lahmek P, Aveyard P. Weight gain in smokers after quitting cigarettes: meta-analysis. BMJ 2012;345:e4439.

[8] Hu Y, Zong G, Liu G, Wang M, Rosner B, Pan A, et al. Smoking cessation, weight change, type 2 diabetes, and mortality. New Engl J Med 2018;379(7):623-32.

[9] Pomerleau CS, Brouwer RJ, Jones LT. Weight concerns in women smokers during pregnancy and postpartum. Addict Behav 2000;25(5):759-67.

[10] Voerman E, Santos S, Inskip H, Amiano P, Barros H, Charles MA, et al. Association of gestational weight gain with adverse maternal and infant outcomes. J Am Med Assoc 2019;321(17):1702-15.

[11] Goldstein RF, Abell SK, Ranasinha S, Misso M, Boyle JA, Black MH, et al. Association of gestational weight gain with maternal and infant outcomes a systematic review and meta-analysis. J Am Med Assoc 2017;317(21):2207-25.

[12] Gaillard R, Durmus B, Hofman A, Mackenbach JP, Steegers EAP, Jaddoe VWV. Risk factors and outcomes of maternal obesity and excessive weight gain during pregnancy. Obesity 2013;21(5):1046-55.

[13] Rode L, Kjaergaard H, Damm P, Ottesen B, Hegaard H. Effect of smoking cessation on gestational and postpartum weight gain and neonatal birth weight. Obstet Gynecol 2013;122(3):618-25.

[14] Adegboye AR, Rossner S, Neovius M, Lourenco PM, Linne Y. Relationships between prenatal smoking cessation, gestational weight gain and maternal lifestyle characteristics. Women Birth 2010;23(1):29-35.

[15] Levine MD, Cheng Y, Cluss PA, Marcus MD, Kalarchian MA. Prenatal smoking cessation intervention and gestational weight gain. Womens Health Issues 2013:23(6):e389-93.

[16] Levine MD, Cheng Y, Marcus MD, Emery RL. Psychiatric disorders and gestational weight gain among women who quit smoking during pregnancy. J Psychosom Res 2015;78(5):504-8.

[17] Restall A, Taylor RS, Thompson JM, Flower D, Dekker GA, Kenny LC, et al. Risk factors for excessive gestational weight gain in a healthy, nulliparous cohort. J Obes 2014;2014:148391.

[18] Rockhill KM, England LJ, Tong VT, Sharma AJ. Biochemically confirmed smoking cessation and gestational weight gain. Birth 2019;46(2):326-34.

[19] Hulman A, Lutsiv O, Park CK, Krebs L, Beyene J, McDonald SD. Are women who quit smoking at high risk of excess weight gain throughout pregnancy? BMC Pregnancy Childbirth 2016;16(1)

[20] Kooijman MN, Kruithof CJ, van Duijn CM, Duijts L, Franco OH, van IMH, et al. The Generation R Study: design and cohort update 2017. Eur J Epidemiol 2016;31(12):1243-64.

[21] Jaddoe VW, Troe EJ, Hofman A, Mackenbach JP, Moll HA, Steegers EA, et al. Active and passive maternal smoking during pregnancy and the risks of low birthweight and preterm birth: the Generation R Study. Paediatr Perinat Epidemiol 2008;22(2):162-71.

[22] Gaillard R, Durmus B, Hofman A, Mackenbach JP, Steegers EA, Jaddoe VW. Risk factors and outcomes of maternal obesity and excessive weight gain during pregnancy. Obesity (Silver Spring) 2013;21(5):1046-55.

[23] Institute of Medicine (US) and National Research Council (US) Committee to reexamine IOM pregnancy weight guidelines. In: Rasmussen KM, Yaktine AL, editors. Weight gain during pregnancy: reexaming the guidelines. Washington (DC): National Academies Press (US); 2009.

[24] Niklasson A, Ericson A, Fryer JG, Karlberg J, Lawrence C, Karlberg P. An update of the swedish reference-standards for weight, length and head circumference at birth for given gestational-age (1977-1981). Acta Paediatr Scand 1991;80(89):756-62.

[25] Smedberg J, Lupattelli A, Mardby AC, Nordeng H. Characteristics of women who continue smoking during pregnancy: a cross-sectional study of pregnant women and new mothers in 15 European countries. BMC Pregnancy Childbirth $2014 ; 14: 213$

[26] Zheng W, Suzuki K, Tanaka T, Kohama M, Yamagata Z, Grp OCHS. Association between maternal smoking during pregnancy and low birthweight: effects by maternal age. PLoS One 2016;11(1)

[27] Campbell EE, Dworatzek PDN, Penava D, de Vrijer B, Gilliland J, Matthews JI, et al. Factors that influence excessive gestational weight gain: moving beyond assessment and counselling. J Matern-Fetal Neonatal Med 2016;29(21):352731.

[28] Harris HE, Ellison GT, Holliday M. Is there an independent association between parity and maternal weight gain? Ann Hum Biol 1997;24(6):507-19.

[29] Suliga E, Rokita W, Adamczyk-Gruszka O, Pazera G, Ciesla E, Gluszek S. Factors associated with gestational weight gain: a cross-sectional survey. BMC Pregnancy Childb 2018;18.

[30] Bauld L, Graham H, Sinclair L, Flemming K, Naughton F, Ford A, et al. Barriers to and facilitators of smoking cessation in pregnancy and following childbirth: literature review and qualitative study. Health Technol Assess 2017;21(36):1-

[31] Hodge AM, Westerman RA, de Courten MP, Collier GR, Zimmet PZ, Alberti KG. Is leptin sensitivity the link between smoking cessation and weight gain? Int J Obes Relat Metab Disord 1997;21(1):50-3.

[32] Berg CJ, Park ER, Chang Y, Rigotti NA. Is concern about post-cessation weight gain a barrier to smoking cessation among pregnant women? Nicotine Tob Res 2008;10(7):1159-63.

[33] Santos S, Voerman E, Amiano P, Barros H, Beilin LJ, Bergstrom A, et al. Impact of maternal body mass index and gestational weight gain on pregnancy 
complications: an individual participant data meta-analysis of European, North American and Australian cohorts. BJOG 2019;126(8):984-95.

[34] Favaretto AL, Duncan BB, Mengue SS, Nucci LB, Barros EF, Kroeff LR, et al. Prenatal weight gain following smoking cessation. Eur J Obstet Gynecol Reprod Biol 2007;135(2):149-53.

[35] Olafsdottir AS, Skuladottir GV, Thorsdottir I, Hauksson A, Steingrimsdottir L. Combined effects of maternal smoking status and dietary intake related to weight gain and birth size parameters. BJOG Int J Obstet Gynaecol 2006;113 (11):1296-302.

[36] England LJ, Levine RJ, Qian C, Morris CD, Sibai BM, Catalano PM, et al. Smoking before pregnancy and risk of gestational hypertension and preeclampsia. Am J Obstet Gynecol 2002;186(5):1035-40.

[37] Li CQ Windsor RA, Perkins L, Goldenberg RL, Lowe JB. The impact on infant birth weight and gestational age of cotinine-validated smoking reduction during pregnancy. JAMA 1993;269(12):1519-24.
[38] Reeves S, Bernstein I. Effects of maternal tobacco-smoke exposure on fetal growth and neonatal size. Expert Rev Obstet Gynecol 2008;3(6):719-30.

[39] Shea AK, Steiner M. Cigarette smoking during pregnancy. Nicotine Tob Res 2008:10(2):267-78

[40] Hakonsen LB, Ernst A, Ramlau-Hansen CH. Maternal cigarette smoking during pregnancy and reproductive health in children: a review of epidemiological studies. Asian J Androl 2014;16(1):39-49.

[41] Nohr EA, Frydenberg M, Henriksen TB, Olsen J. Does low participation in cohort studies induce bias? Epidemiology 2006;17(4):413-8.

[42] England LJ, Grauman A, Qian C, Wilkins DG, Schisterman EF, Yu KF, et al. Misclassification of maternal smoking status and its effects on an epidemiologic study of pregnancy outcomes. Nicotine Tob Res 2007;9(10):1005-13.

[43] Klebanoff MA, Levine RJ, Morris CD, Hauth JC, Sibai BM, Ben Curet L, et al, Accuracy of self-reported cigarette smoking among pregnant women in the 1990s. Paediatr Perinat Epidemiol 2001;15(2):140-3. 